\section{Thyroid traps that every psychiatrist should be aware of}

\author{
As armadillhas da tireóide às quaís todo \\ psiquiatra deve estar atento
}

\section{Dear Editor}

Psychiatric disorders may be secondary to endocrinological diseases what may be represented by the association between thyroid gland function and behavior manifestations. Thyroid hormones are widely arranged in brain and may influence some psychic symptoms, mainly by changing neurotransmitters' release. ${ }^{1}$

We would like to report a case of a high school student, 17 years old, who presented with agitation, insomnia, tremors, disinhibited behavior, exalted mood, grandiose delusion and auditory hallucinations for three months. He had never been in a psychiatry service before. His relatives reported no family history of psychiatric disorder. In admission, the patient exhibited an expansive attitude, dysphoria and accelerated thoughts. He reported diary cannabis abuse for the last year. After one month using risperidone $2 \mathrm{mg}$ every day the patient returned home with remission of all psychotic symptoms, but still presented exalted mood. His follow-up in the outpatient clinic evidenced tremors, hypertension (AP 140x100mmHg) and tachycardia (CF 110bpm) for two months. Laboratory tests showed elevated thyroxin and reduced $\mathrm{TSH}$. The patient received propiltiouracil and propranolol and after 45 days he presented remission of physical and psychic symptoms, besides stopping cannabis use.

There have been reports showing association between hyperthyroidism and cannabis abuse as well as with psychiatric disorders. ${ }^{1-3}$ Yet, there has been no association between cannabis use and hyperthyroidism. Animal models, however, demonstrated that acute cannabinoid administration disrupts many hormone systems, including suppression of gonadal steroids, growth hormone, prolactin and thyroid hormones, besides the hypothalamic-pituitary-adrenal axis. These effects are caused by endogenous cannabinoid receptors located close to and inside the hypothalamus. ${ }^{4}$

Although all the consequences of chronic cannabis use in human endocrine system are still unclear, there is evidence that in thyrotoxicosis the number of binding sites for catecholamines increases. This report shows the importance of laboratory tests for thyroid diseases in patients with mood disorders. ${ }^{4}$ Establishing a differential diagnosis is essential to conduct the best psychopharmacological treatment aiming at the best treatment 
response. ${ }^{2}$ We conclude by saying that it is advisable to consider thyroid dysfunction as an important differential diagnosis or associated comorbidity in drug abuse.

Leonardo Baldaçara

Universidade Federal de Tocantins (UFT), Palmas (TO), Brazil

Universidade Federal de São Paulo (Unifesp),

São Paulo (SP), Brazil

Integrated Mental Health Care Center, Santa Casa de São Paulo,

São Paulo (SP), Brazil

Débora Naomi de Souza, Roberto Canton, Lilian Ratto Integrated Mental Health Care Center, Santa Casa de São Paulo,

São Paulo (SP), Brazil

\section{Disclosures}

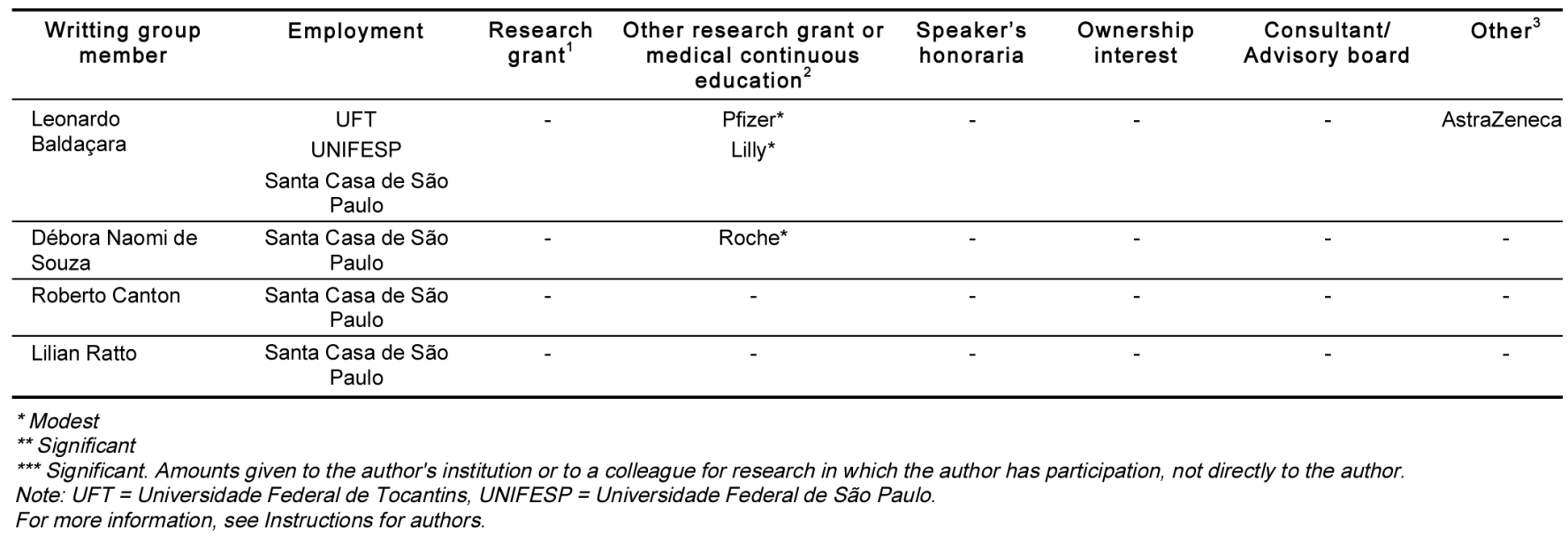

\section{References}

1. Bauer M, London ED, Silverman DH, Rasgon N, Kirchheiner J, Whybrow PC. Thyroid, brain and mood modulation in affective disorder: insights from molecular research and functioning brain imaging. Pharmacopsychiatry. 2003;36 Suppl 3:215-21.

2. Ben MA, Potvin S. Cannabis and psychosis: what is the link? J Psychoactive Drugs. 2007;39(2):131-42.
3. Brownlie BE, Rae AM, Walshe JW, Wells JE. Psychoses associated with thyrotoxicosis - 'thyrotoxic psychosis.' A report of 18 cases, with statistical analysis of incidence. Eur J Endocrinol. 2000;142(5):438-44.

4. Brown TT, Dobs AS. Endocrine effects of marijuana. J Clin Pharmacol. 2002;42(Suppl 11):S90-6. 